DOI: 10.2478/lpts-2019-0024

SOLID STATE PHYSICS

\title{
COMPUTER SIMULATIONS OF THE BAND STRUCTURE AND DENSITY OF STATES OF THE LINEAR CHAINS OF NaCl IONS
}

\author{
L.N. Myasnikova ${ }^{1}$, A.S. Istlyaup ${ }^{1}$, D.M. Sergeyev ${ }^{1,2}$, N.N. Zhanturina ${ }^{1}$, \\ K.Sh. Shunkeyev ${ }^{1}$, A.I. Popov ${ }^{3}$ \\ ${ }^{1}$ Zhubanov Aktobe Regional State University, 34 A.Moldagulova Ave., Aktobe, \\ 030000, KAZAKHSTAN \\ ${ }^{2}$ Begeldinov Military Institute of Air Defence Forces, 39 Moldagulova Ave., \\ Aktobe, 030012, KAZAKHSTAN \\ ${ }^{3}$ Institute of Solid State Physics, University of Latvia, 8 Kengaraga Str., LV-1063 \\ LATVIA \\ e-mail:myasnikova_ln@mail.ru,popov@latnet.lv
}

The paper presents the results of first-principles computer simulations of the band structure, the density of states, and the total energy of $\mathrm{NaCl}(\mathrm{NaCl}$, $\mathrm{Na}_{2} \mathrm{Cl}_{2}, \mathrm{Na}_{3} \mathrm{Cl}_{3}, \mathrm{Na}_{4} \mathrm{Cl}_{4}, \mathrm{Na}_{6} \mathrm{Cl}_{6}$ ) linear chains of atoms. Modelling of the specified characteristics is realised in the computer code Atomistix ToolKit combined with Virtual NanoLab. The total energy depends on the number of ions in the nanoobject under study, but practically does not depend on the geometric arrangement of ions.

Keywords: $\mathrm{NaCl}$, band structure, computer simulations, density of states, total energy

\section{INTRODUCTION}

Alkali halides are the simplest and most representative ionic crystals. The alkali halides $\mathrm{NaF}, \mathrm{NaCl}, \mathrm{NaBr}$, and $\mathrm{NaI}$ crystallize in the rock salt (B1) structure at ambient conditions. They have many interesting physical properties such as high melting point, strong miscibility, and large band gaps. Due to the fact that in these materials the effective exciton mechanism [1]-[10] of the formation of radiation defects is implemented, they are widely used as radiation detectors, such as scintillators [11]-[15] and a storage phosphors for image plate detectors and optically stimulated dosimeters [16]-[20]. Moreover, alkali halides are used as infrared (IR) optical windows and optoelectronic devices [21], [22].

Nowadays, the properties of alkali halide nanocrystals have attracted great 
attention of experts in chemistry, physics, and engineering. Structural, electronic, dynamic, and chemical characteristics of materials depend primarily on the state (phase) and the degree (size) of aggregation. Atomic chains containing 3-500 particles exhibit unique physical and chemical phenomena, which are of both fundamental and technological significance, and provide ways and means to explore the "transition" from molecular to condensed-matter systems [23]. They are simultaneously regarded as fundamental objects, in which the molecular and solid properties are reflected [24]-[29]. There are three main areas of application: first, nanocrystalline structures represent the ultimate in miniaturization of solid-state materials. Second, many nanocrystal properties are dominated by their surfaces because a large fraction of the atoms lies in the outermost layer. Third, the finite size and number of atoms in a nanocrystal, which is often less than $10^{3}$, mean that systems having the structures of bulk crystalline matter can be calculated with a precision typically reserved for atoms and molecules, using modern methods [30], [31].

In the last decade, many papers were published about the properties of alkali halide nanocrystals. They include results on the cohesion, bonding, and structures; crystallinity phenomena including cleaving and melting; molecular adsorption reactions; halide-transfer reactions; electron substitution, solvation, and spectroscopy; surface electron states; electronic excitations and photochemistry; multiple charging; and other subtle effects in nanolattices [23], [32]. However, some major issues remain open, such as the reliability of structural calculations, based on first-principles methods. With these calculations, most experimental results could be interpreted.

A deep understanding of the optical properties of solids is impossible without a detailed knowledge of their electronic structure. The electronic processes in ionic crystals are considered on the basis of the approximate quantum-mechanical theory where the motion of electrons and nuclei is separated based on adiabatic BornOppenheimer approximation [33], [34]. One of the characteristics of the reflecting property of a nano-objects is the electronic density of states: the number of allowed electron (or hole) states per volume for a given energy [31].

In this paper, an attempt was made to determine the band structure, the density of states, and the total energy of $\mathrm{NaCl}$ linear chains with different number of ions using the computer simulations of Atomistix ToolKit combined with Virtual NanoLab [35].

\section{DESCRIPTION OF THE OBJECT AND METHODS OF RESEARCH}

The isolated atoms of the alkali metal $\mathrm{Na}$ and the halogen $\mathrm{Cl}$ have the following electronic configuration: $\mathrm{Na}^{0}-1 \mathrm{~s}^{2} 2 \mathrm{~s}^{2} 2 \mathrm{p}^{6} 3 \mathrm{~s}^{1}, \mathrm{Cl}^{0}-1 \mathrm{~s}^{2} 2 \mathrm{~s}^{2} 2 \mathrm{p}^{6} 3 \mathrm{~s}^{2} 3 \mathrm{p}^{5}$. In $\mathrm{NaCl}$ matrix, the ions of the corresponding elements assume the following electronic configuration $\mathrm{Na}^{+}-1 \mathrm{~s}^{2} 2 \mathrm{~s}^{2} 2 \mathrm{p}^{6}, \mathrm{Cl}^{-}-1 \mathrm{~s}^{2} 2 \mathrm{~s}^{2} 2 \mathrm{p}^{6} 3 \mathrm{~s}^{2} 3 \mathrm{p}^{6}$. As a result, the valence electron located on the outer shell of $\mathrm{Na}^{0}$ completely passes to $\mathrm{Cl}^{0}$.

We divided the studied $\mathrm{NaCl}$ objects into three categories: one-dimensional, two-dimensional and three-dimensional. The dimensional $\mathrm{NaCl}$ built chain of 2, 4, 6 and 12, alternating between a $\mathrm{Na}^{+}$ions and $\mathrm{Cl}^{-}$. Plane of 4, 6, 8 and 12 ions are 
constructed in the two-dimensional $\mathrm{NaCl}$. Three-dimensional $\mathrm{NaCl}$ consists of 8 and 12 ions. The distance between the centres of the nearest ions in $\mathrm{NaCl}$ is $2.82 \AA$ [36].

In the adiabatic approximation, the solution of the Schrödinger equation shows that the states of an excess electron in a crystal with a periodic field are described by the Bloch wave functions [37]

$$
u_{k}(\vec{r}) \exp \left\{-i\left(\frac{E}{h} t-\vec{k} \vec{r}\right)\right\} \text {, }
$$

where the function $u_{k}(\vec{r})$ has the translational symmetry of the lattice, $E$ - energy, $\vec{k}$-wave vector. For a face-centered alkali halide crystal, the first Brillouin zone is a fourteen-tetrahedron in the form of a truncated octahedron; six faces have the form of squares, eight - the form of regular hexagons. The $\Gamma$-point lies in the centre of the first Brillouin zone $(k=0)$, the X-point lies in the centre of the square plane, the L-point is at the centre of the hexagon. Along the [100] axis, the value of the wave vector varies from 0 to $k_{\mathrm{x}}$, along the [111] direction from 0 to $k_{\mathrm{L}}$. In all alkali halide crystals, the maximum of the valence band and the minimum of the conduction band are located in the centre of the Brillouin zone ( $\Gamma$ point). The upper hole zones are formed from the $p$-states of the halogen and have a negative dispersion typical of the $p$-bands. The bottom of the conduction band has an $s$-character, the effective mass of the electron is isotropic and has a value of the order of (0.5-1) $m_{0}$.

Computer modelling was carried out within the framework of the density functional theory (DFT) in the local density approximation [38].

\section{RESULTS AND DISCUSSION}

The calculated band structure of one-dimensional $\mathrm{NaCl}$ is shown in Fig. 1. The calculated band gap for a chain of two ions is $10.25 \mathrm{eV}$, of four ions $-11.4 \mathrm{eV}$, of six $-8.45 \mathrm{eV}$ and of twelve $-10.46 \mathrm{eV}$. Note that in the first case, the energy minimum is observed at the $\Gamma$ point of the Brillouin zone. The upper valence band in alkali halide crystals is associated with $p$-states of halogen. Function $E(k)$ has a maximum at the $\Gamma$-point. Due to the spin-orbit interaction for the $p$-hole at the $\Gamma$-point, the zone is split into two components. For the upper component, the orbital and spin moments of the $p$-hole are parallel and $j^{+}=3 / 2$. For the lower component, the orbital and spin moments are antiparallel and $j^{+}=1 / 2$. At the $\Gamma$-point, the upper component can degenerate. At the X-and L-points of the Brillouin zone, the valence band splits into three components. The lowest valence band occurs mainly from the $s$-orbit of $\mathrm{Cl}$ halogen, while the chlorine $p$-orbit is very weakly bound to the $p$-state of $\mathrm{Na}$, as can be seen from the density of states (Fig. 2). In Fig. $2 a$, we observe two peaks responsible for $s$-orbits. The peak near $-12 \mathrm{eV}$ is connected with the halogen $\mathrm{Cl}$, and the peak in the vicinity of zero energy is connected with Na. Figure $2 b$ presents $p$-states of $\mathrm{NaCl}$. 

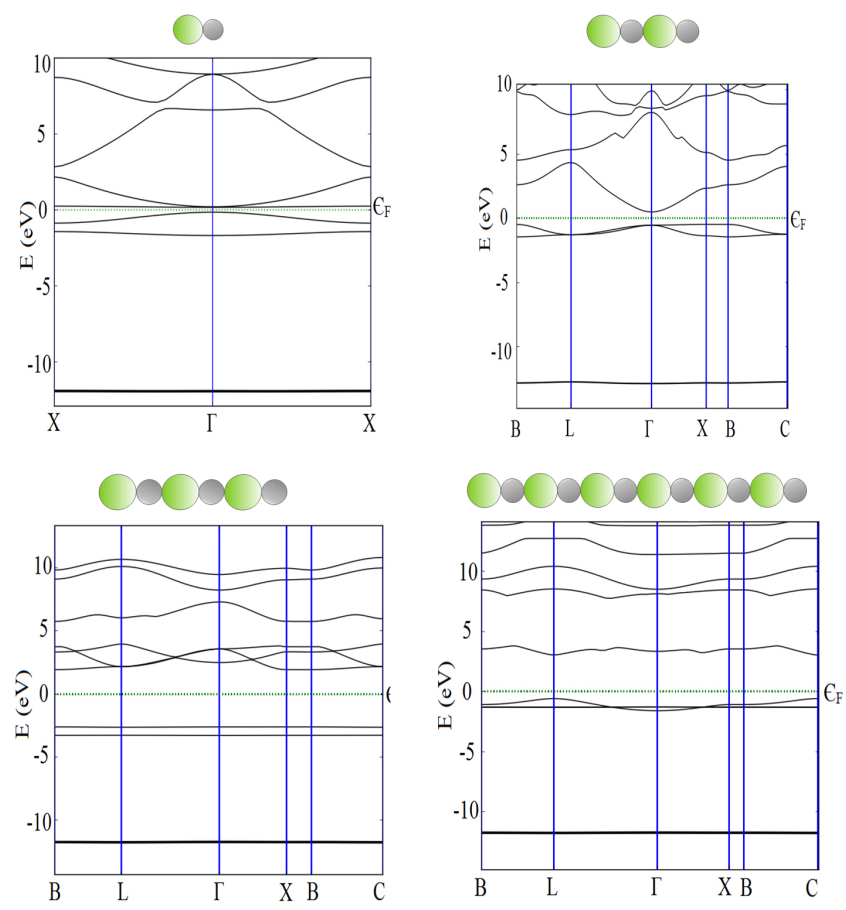

Fig. 1. Band structure of one-dimensional $\mathrm{NaCl}$.

(Grey balls are sodium ions, green balls are chlorine ions)

The calculated band gap for $\mathrm{NaCl}$, constructed on a plane of four ions, is $11.83 \mathrm{eV}$, of six $-11.46 \mathrm{eV}$, of eight $-11.55 \mathrm{eV}$ and of twelve $-12.09 \mathrm{eV}$ (Fig. 3). Note that the same for the bulk NaCl constructed from eight ions is $11.92 \mathrm{eV}$ and from twelve to $11.12 \mathrm{eV}$ (Fig. 3). Note that the experimental band gap energy for lowest-energy direct transition in crystalline $\mathrm{NaCl}$ was estimated to be $8.97 \pm 0.07 \mathrm{eV}$ at $77^{\circ} \mathrm{K}[39]$.

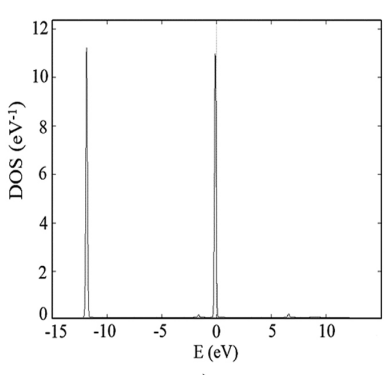

a)

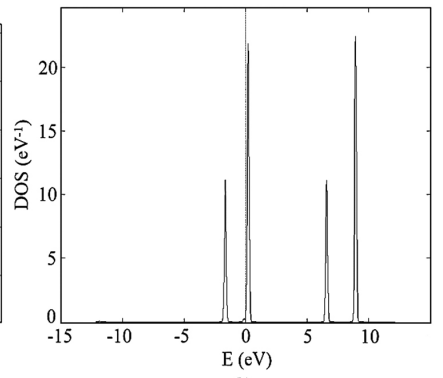

b)

Fig. 2. Density of s (a), p (b) states of $\mathrm{NaCl}$, consisting of one sodium ion and one chloride ion.

Table 1 shows the total energy of $\mathrm{NaCl}$ in 1-, 2- and 3- dimensions. We note that the value of the total energy depends on the number of ions in the object under study, but practically does not depend on the geometric arrangement of ions in space. At the same time, the values of the total energy vary in a narrow range, from -2815.15010 to $-466.49970 \mathrm{eV}$. As we see from Table 1, with the increase in the 
number of ions, the total energy decreases. For comparison, in $\mathrm{Na}_{4} \mathrm{Cl}_{3}$ cluster the total energy is higher to one order [31].

Table 1

\section{Total and Specific Energy of $\mathrm{NaCl}$}

\begin{tabular}{|l|c|c|c|}
\hline Object & Geometric location & Total energy, eV & Specific energy, eV \\
\hline $\mathrm{NaCl}$ & 1D & -466.49970 & -233.24985 \\
\hline $\mathrm{Na}_{2} \mathrm{Cl}_{2}$ & 2D & -934.20591 & -233.55148 \\
\hline $\mathrm{Na}_{2} \mathrm{Cl}_{2}$ & 1D & -934.68737 & -233.67184 \\
\hline $\mathrm{Na}_{3} \mathrm{Cl}_{3}$ & 2D & -1398.40833 & -233.06806 \\
\hline $\mathrm{Na}_{3} \mathrm{Cl}_{3}$ & 1D & -1398.79007 & -233.13117 \\
\hline $\mathrm{Na}_{4} \mathrm{Cl}_{4}$ & 2D & -1864.85786 & -233.10723 \\
\hline $\mathrm{Na}_{4} \mathrm{Cl}_{4}$ & 3D & -1876.45384 & -234.55673 \\
\hline $\mathrm{Na}_{6} \mathrm{Cl}_{6}$ & 1D & -2754.87862 & -229.57322 \\
\hline $\mathrm{Na}_{6} \mathrm{Cl}_{6}$ & 2D & -2795.56555 & -232.96380 \\
\hline $\mathrm{Na}_{6} \mathrm{Cl}_{6}$ & 3D & -2815.15010 & -234.59584 \\
\hline
\end{tabular}
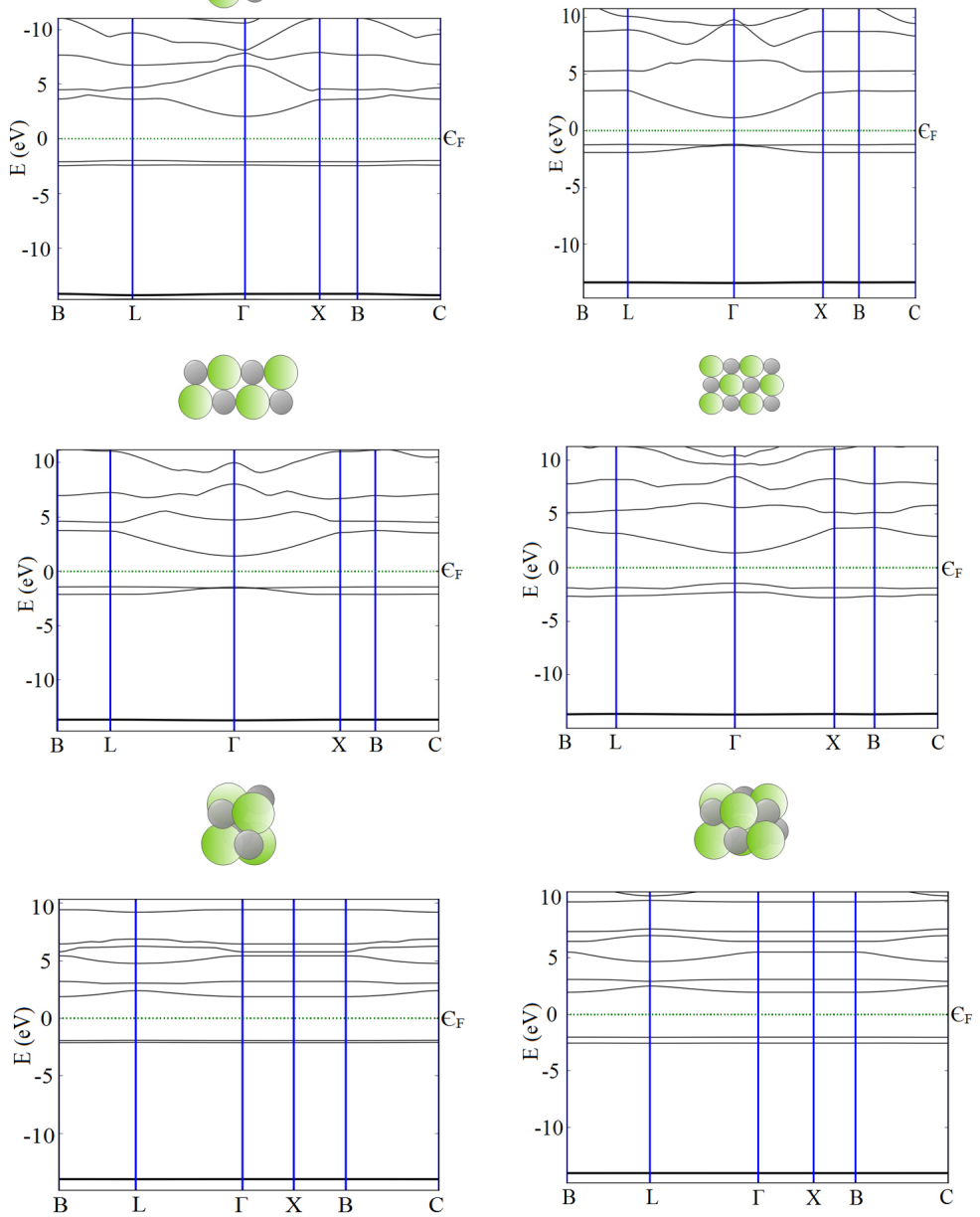

Fig. 3. Band structure of two-dimensional and three-dimensional $\mathrm{NaCl}$. 


\section{CONCLUSIONS}

In this paper, we presented the results of computer simulations of the band structure, the density of states, and the total energy of $\mathrm{NaCl}$ linear chains with different ion number $\left(\mathrm{NaCl}, \mathrm{Na}_{2} \mathrm{Cl}_{2}, \mathrm{Na}_{3} \mathrm{Cl}_{3}, \mathrm{Na}_{4} \mathrm{Cl}_{4}, \mathrm{Na}_{6} \mathrm{Cl}_{6}\right)$, depending on the geometric arrangement of ions.

Objects with a small number of atoms often exhibit thermodynamic, structural, energetic, dynamic, electronic, and chemical properties, which differ considerably from bulk materials, reflecting the finite-size of these systems. The simulation of the above-mentioned properties of $\mathrm{NaCl}$ chains may be useful for the calculation of energetical properties of alkali halide nanocrystals.

\section{ACKNOWLEDGEMENTS}

The authors thank Eugene Kotomin and V. Kuzovkov for fruitful discussions and valuable suggestions. A.I.P thanks A.Moskina for the technical assistance in preparation of the manuscript. A.I.P also gratefully acknowledges a project LZP2018/1-0214 from the Latvian Council of Science for partial support.

\section{REFERENCES}

1. Lushchik, C., Kolk, J., Lushchik, A., Lushchik, N., Taiirov, M., \& Vasilchenko, E. (1982). Decay of excitons into long-lived F, H and $\alpha$, I pairs in KCl. Physica Status Solidi (b), 114(1), 103-111.

2. Lushchik, C., Kolk, J., Lushchik, A., \& Lushchik, N. (1984). Radiational creation of Frenkel defects in KCl- Tl. Physica Status Solidi (a), 86(1), 219-227.

3. Lushchik, A. C., \& Frorip, A. G. (1990). Thermalized and hot interstitial halogen ions in alkali halides. Physica Status Solidi (b), 161(2), 525-535.

4. Popov, A. I., Kotomin, E. A., \& Maier, J. (2010). Basic properties of the F-type centers in halides, oxides and perovskites. Nuclear Instruments and Methods in Physics Research Section B: Beam Interactions with Materials and Atoms, 268(19), 3084-3089.

5. Eglitis, R. I., Popov, A. I., \& Kotomin, E. A. (1995). Computer simulations of I-center annealing in $\mathrm{KCl}$ and $\mathrm{KBr}$ crystals. Theoretical interpretation of thermostimulated experiments. Physica Status Solidi (b), 190(2), 353-362.

6. Kuzovkov, V. N., Popov, A. I., Kotomin, E. A., Moskina, A. M., Vasilchenko, E., \& Lushchik, A. (2016). Theoretical analysis of the kinetics of low-temperature defect recombination in alkali halide crystals. Low Temperature Physics, 42(7), 588-593.

7. Lushchik, A., Lushchik, Ch., Vasil'chenko, E., \& Popov, A. (2018). Radiation creation of cation defects in alkali halide crystals: Review and today's concept. Low Temperature Physics, 44, 357-367.

8. Kotomin, E., Popov, A., \& Hirai, M. (1994). A contradiction between pulsed and steadystate studies in the recombination kinetics of close Frenkel defects in $\mathrm{KBr}$ and $\mathrm{KCl}$ crystals. Journal of the Physical Society of Japan, 63(7), 2602-2611.

9. Kotomin, E. A., Popov, A. I., \& Eglitis, R. I. (1992). Correlated annealing of radiation defects in alkali halide crystals. Journal of Physics: Condensed Matter, 4(27), 59015910 . 
10. Szymonski, M., Droba, A., Struski, P., \& Krok, F. (2012). Dynamics of the defectmediated desorption of alkali halide surfaces. Low Temperature Physics, 38(8), 774-778.

11. Chernov, S. A., Trinkler, L., \& Popov, A. I. (1998). Photo-and thermo-stimulated luminescence of CsI-Tl crystal after UV light irradiation at $80 \mathrm{~K}$. Radiation Effects and Defects in Solids, 143(4), 345-355.

12. Popov, A. I., Chernov, S. A., \& Trinkler, L. E. (1997). Time-resolved luminescence of CsI-Tl crystals excited by pulsed electron beam. Nuclear Instruments and Methods in Physics Research Section B: Beam Interactions with Materials and Atoms, 122(3), 602605.

13. Popov, A. I., \& Balanzat, E. (2000). F centre production in CsI and CsI-Tl crystals under $\mathrm{Kr}$ ion irradiation at $15 \mathrm{~K}$. Nuclear Instruments and Methods in Physics Research Section B: Beam Interactions with Materials and Atoms, 166, 545-549.

14. Totsuka, D., Yanagida, T., Fujimoto, Y., Yokota, Y., Moretti, F., Vedda, A., \& Yoshikawa, A. (2012). Afterglow suppression by co-doping with Bi in CsI: Tl crystal scintillator. Applied Physics Express, 5(5), 052601.

15. Rogulis, U., Spaeth, J. M., Elsts, E., \& Dolgopolova, A. (2004). Tl-related radiation defects in CsI: Tl. Radiation Measurements, 38(4-6), 389-392.

16. Zorenko, Y. V., Turchak, R. M., Gryk, W., \& Grinberg, M. (2004). Luminescent spectroscopy of $\mathrm{Eu}^{2+}$ centers in $\mathrm{CsBr}$ : Eu single crystals at $10-550 \mathrm{~K}$. Journal of Luminescence, 106(3-4), 313-320.

17. Trinkler, L. E., Trinkler, M. F., \& Popov, A. I. (1993). Stimulation energy of the X-ray storage material KBr: In. Physica Status Solidi (b), 180(1), K31-K34.

18. Schweizer, S. (2001). Physics and current understanding of X-ray storage phosphors. Physica Status Solidi (a), 187(2), 335-393.

19. Popov, A. I., \& Plavina, I. (1995). Photostimulated emission of $\mathrm{KBr}$ - In previously exposed to UV-or X-radiation. Nuclear Instruments and Methods in Physics Research Section B: Beam Interactions with Materials and Atoms, 101(3), 252-254.

20. Halliday, M. T. E., Hess, W. P., \& Shluger, A. L. (2015). Structure and properties of electronic and hole centers in $\mathrm{CsBr}$ from theoretical calculations. Journal of Physics: Condensed Matter, 27(24), 245501.

21. Armington, A. F., Posen, H., \& Lipson, H. (1973). Strengthening of halides for infrared windows. Journal of Electronic Materials, 2(1), 127-136.

22. Kumar, A., Ravindra, N., \& Rath, R. (1979). Optoelectronic properties of alkali halides. Journal of Physics and Chemistry of Solids, 40(12), 1141-1142.

23. Uzi, L., Scharf, D., \& Jortner, J. (1985). Electron localization in alkali-halide clusters. Physical Review Letters, 54(16), 1860-1863.

24. Whetten, R.L. (1993). Alkali Halide Nanocrystals. Acc. Chem. Rev., 26, 49-56.

25. Lisitsyn, V., Lisitsyna, L., \& Polisadova, E. (2015). Nanodefect substructures in crystal phosphors. IOP Conference Series: Materials Science and Engineering, 81(1), 012020.

26. Babin, V., Elango, A., Kalder, K., Maaroos, A., Shunkeev, K., Vasilchenko, E., \& Zazubovich, S. (1999). Luminescent defects created in alkali iodides by unelastic uniaxial deformation at 4.2K. J. Luminescence, 81, 71-77.

27. Shunkeyev, K., Sergeyev, D., Myasnikova, L., Barmina, A., Shunkeyev, S., Zhanturina, N., \& Aimaganbetova, Z. (2014). Vacancy dipole currents of thermostimulated depolarization in a plastically deformed $\mathrm{KCl}$ crystal. Russian Physics Journal, 57(4), 451-458.

28. Kotomin, E. A., Kuzovkov, V. N., \& Popov, A. I. (2001). The kinetics of defect aggregation and metal colloid formation in ionic solids under irradiation. Radiation Effects and Defects in Solids, 155(1-4), 113-125. 
29. Shunkeev, K., Sarmukhanov, E., Barmina, A., Myasnikova, L., Sagimbaeva, Sh., \& Shunkeev, S. (2008). Specific features of the temperature quenching of luminescence of self-trapped excitons in alkali halide crystals under low-temperature deformation. Phys. Solid State, 50(10), 1799-1802.

30. Wang, F., \& Landau, D.P. (2001). Efficient, multiple-range random walk algorithm to calculate the density of states. Phys. Rev. Lett. American Physical Society, 86, 2050 2053.

31. Kaukonen, H.-P., Landman, U., \& Cleveland, C.L. (1991). Reactions in clusters. J. Chem. Phys., 95, 4997-5013.

32. Heidorn, S.-Ch., Bertram, C., Cabrera-Sanfelix, P., \& Morgenstern, K. (2015). Consecutive mechanism in the diffusion of $\mathrm{D}_{2} \mathrm{O}$ on $\mathrm{NaCl}$ (100) bilayer. ACS Nano, 9(4), 3572-3578.

33. Hoya, J., Laborde, J.I., Richard, D., \& Rentería, M. (2017). Ab initio study of F-centers in alkali halides. Computational Materials Science, 139, 1-7.

34. Valeev, F., \& Sherrill, C. D. (2003). The diagonal Born-Oppenheimer correction beyond the Hartree-Fock approximation. The Journal of Chemical Physics, 118 (9), 10.1063/1.1540626.

35. Atomistix ToolKit. Manual Version 2015.1., 840 (QuantumWise A/S: 2015).

36. Cherepanov, A.N., \& Shul'gin, B.V.(2005). Utochneniye raschetnykh znacheniy radiusov ionov shchelochnogaloidnykh soyedineniy. Problemy spektroskopii: mezhvuzovskiy sbornik nauchnykh trudov, Yekaterinburg, 19, 77-86.

37. Sharma, S., Dewhurst, J. K., Lathiotakis, N. N., \& Gross, E. K. (2008). Reduced density matrix functional for many-electron systems. Phys. Rev., B 78, 201103(R).

38. Kohn, W.A., Becke, D., \& Parr, R.G. (1996). Density functional theory of electronic structure. J. Phys. Chem., 100, 12974-12980.

39. Roessler, D. M., \& Walker, W. C. (1968). Electronic spectra of crystalline $\mathrm{NaCl}$ and $\mathrm{KCl}$. Physical Review, 166(3), 599.

\title{
ELEKTRONISKO JOSLU STRUKTŪRAS UN STĀVOKḶU BLĪVUMA DATORMODELĒŠANA NaCl JONU LINEĀRAJĀM ĶĒDĒM
}

\author{
L.N. Mjasņikova, A.S. Isțlaup, D.M. Sergejevs, N.N. Žanturina, \\ K.Š. Šunkejevs, A.I. Popovs
}

Kopsavilkums

Pētījumā sniegtas $\mathrm{NaCl}\left(\mathrm{NaCl}, \mathrm{Na}_{2} \mathrm{Cl}_{2}, \mathrm{Na}_{3} \mathrm{Cl}_{3}, \mathrm{Na}_{4} \mathrm{Cl}_{4}, \mathrm{Na}_{6} \mathrm{Cl}_{6}\right)$ lineāro atomu ķēdes elektroniskās joslas struktūras, stāvokḷu blīvuma un pilnas energijas pirmo principu datormodelēšanas rezultāti. Norādīto īpašību modelēšana tiek realizēta ar datora kodu Atomistix ToolKit apvienojumā ar Virtual NanoLab. Kopējā enerğija ir atkarīga no pētāmā nanoobjekta jonu skaita, bet praktiski nav atkarīga no jonu ǵeometriskā izkārtojuma.

26.07.2019. 